\title{
A Case of Thyroarytenoid Myectomy with Selective Recurrent Laryngeal Nerve Section in Intractable Spasmodic Dysphonia: A Long-Term Follow-Up
}

\author{
Yun Ji Lee (D), You Young An (D), Ki Nam Park DiD, and Seung Won Lee (iD) \\ Department of Otorhinolaryngology-Head and Neck Surgery, Soonchunhyang University College of Medicine, Bucheon Hospital, Bucheon, Korea \\ 난치성 연축성 발성장애 환자에서 갑상피열근 절제술 및 선택적 반회후두신경 절제술 1 예: 장기 추적 관찰 \\ 이윤지, 안유영, 박기남, 이승원 \\ 순천향대학교 의과대학 부천병원 이비인후-두경부외과학교실
}

\begin{abstract}
Spasmodic dysphonia is a disease presumed to be a form of focal laryngeal dystonia. The widely used first-line treatment is botulinum toxin injection to the thyroarytenoid muscles. In spite of the effectiveness and safety of this method, it has a temporary effect that lasts only several months, resulting the patients' symptom fluctuating, called 'Botox rollercoaster.' Some surgical techniques had tried, but they had shown several limitations including high rate of recurrence. We tried thyroarytenoid myectomy with selective recurrent laryngeal nerve section in a patient with intractable spasmodic dysphonia. This procedure is an alternative treatment of spasmodic dysphonia to prevent recurrence and improve symptoms. During five years of follow-up, she has shown steady quality voice without any complication. To the best of our knowledgement, this is the longest follow-up case of this operation in South Korea.
\end{abstract}

Keywords Spasmodic dysphonia; Thyroarytenoid myectomy; Botulinum toxin injection.

\section{서 론}

연축성 발성장애(spasmodic dysphonia)는 발성 시에 후두 근육의 불수의적인 연축 에 의해 음성 단절(break), 긴장성 노력음(strained strangled voice), 음성 떨림(voice tremor)을 보이는 발성장애이다. ${ }^{1)}$ 근본적인 원인은 밝혀져 있지 않아 보툴리눔 독소 주 입술(botulinum toxin injection)이 증상 호전을 위한 일차 치료로 널리 사용되고 있 다.) 그러나 이는 효과가 일시적이어서 반복적인 시술이 필요할 뿐만 아니라, 음성의 변 동성으로 인해 환자의 삶의 질을 떨어뜨리고 환자 간에 시술 효과의 차이를 보인다는 제한점을 가진다. 본 증례는 난치성 연축성 발성장애 환자에서 Tsuji 등에에 의해 기술 된 갑상피열근 절제술 및 선택적 반회후두신경 절제술(thyroarytenoid myectomy with selective recurrent laryngeal nerve section)을 시도하여 국내에서 최초로 5년 간의 장기 추적 관찰 결과 재발 및 합병증의 동반 없이 효과적인 음성 개선을 유지하고

\author{
Received April 10, 2020 \\ Revised April 21, 2020 \\ Accepted April 22, 2020
}

\section{Corresponding Author} Seung Won Lee, MD, PhD Department of OtorhinolaryngologyHead and Neck Surgery, Soonchunhyang University College of Medicine,

Bucheon Hospital, 170 Jomaru-ro Bucheon 14584, Korea

Tel $+82-32-621-5448$

Fax $+82-32-621-5016$

E-mail Isw0922@schmc.ac.kr

\section{ORCID iDs}

Yun Ji Lee (D)

https://orcid.org/0000-0002-6238-1801 You Young An (i) https://orcid.org/0000-0001-6695-7655 Ki Nam Park (D)

https://orcid.org/0000-0001-6641-3981

Seung Won Lee (iD)

https://orcid.org/0000-0002-0468-8143

This is an Open Access article distributed under the terms of the Creative Commons Attribution Non-Commercial License (https://creativecommons.org/ licenses/by-nc/4.0) which permits unrestricted non-commercial use, distribution, and reproduction in any medium, provided the original work is properly cited. 

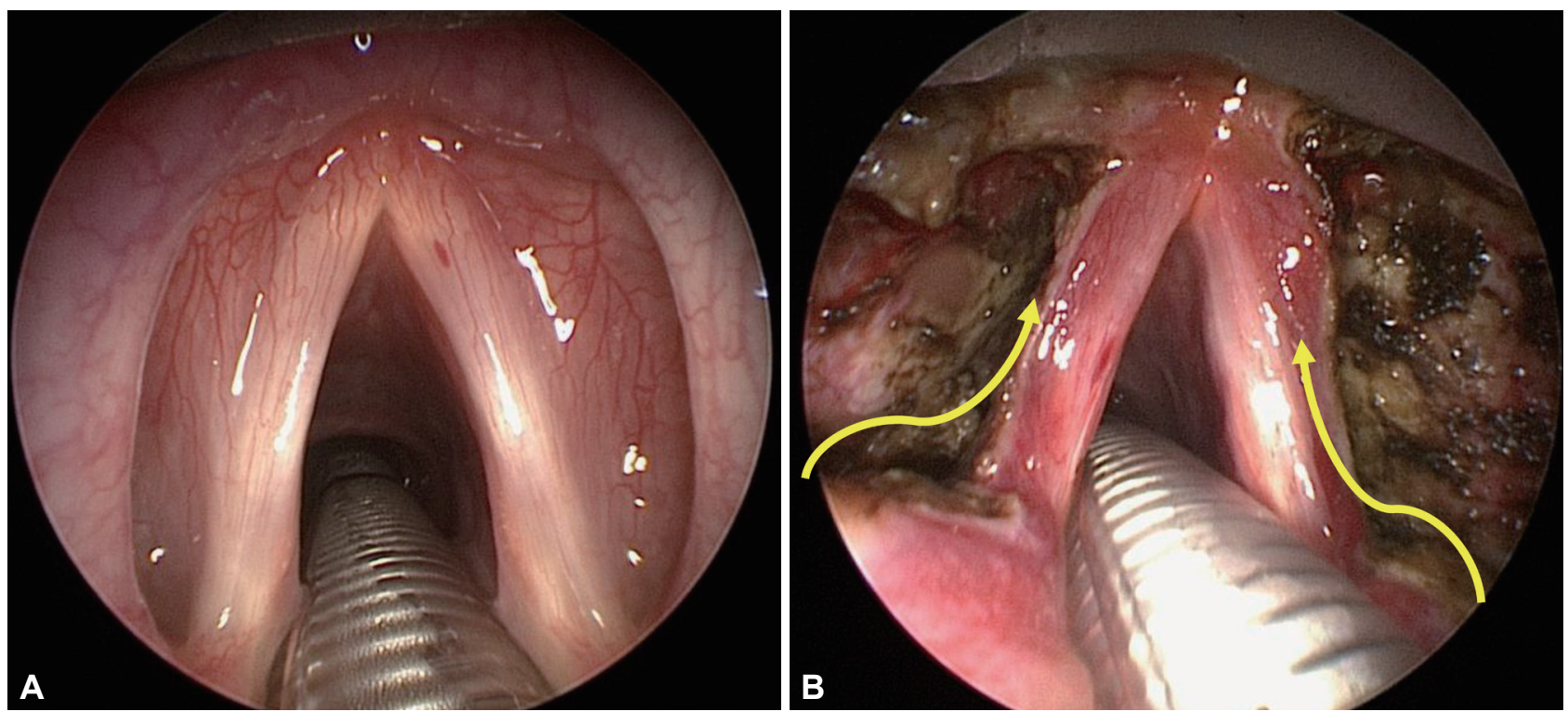

Fig. 1. Intraoperative endoscopic view. The larynx is exposed by suspension laryngoscope under general anesthesia (A). This endoscopic finding shows after bilateral thyroarytenoid muscles including vestibular folds are resected by $\mathrm{CO}_{2}$ laser and the nerve endings are cut off (B). The yellow arrow indicates the pathway of the terminal ends of recurrent laryngeal nerves.

있는 환자를 경험하여 이를 문헌과 함께 고찰하려 한다.

\section{증 례}

특이 내과적 과거력 없는 49세 여성이 15년 이상 지속된 목소리 떨림을 주소로 10년 전 타 병원에서 성대근 보툴리눔 독소 주입술을 2차례 시행 받았으나 증상이 지속되어 본원 에 내원하였다. 굴곡 후두 내시경 및 후두 스트로보스코피 검사상 후두의 구조적인 이상 소견은 없었으나 발성 시에 후 두 근육의 과도한 수축 및 이로 인한 음성의 불규칙한 떨림 (voice tremor)이 확인되었다. 특징적으로 대화시에 쥐어짜 는 목소리(strained voice)와 음성의 단절(voice break) 소견 을 동반하여 연축성 발성장애로 진단하였으며, 본원에서 5 차 례 추가로 성대근 보툴리눔 독소 주입술을 시행하였다. 환자 는 시술 후 수 주일간 음성의 불규칙한 떨림과 단절 증상이 일시적으로 호전되었다가 다시 악화되는 것이 반복되고, 각 시술 시의 효과 또한 일정하지 않다고 호소하였다. 또한, 자 영업자로 직업력상 음성 사용이 필수적인 자로서 시술 이후 발생하는 기식성 음성(breathy voice) 및 흡인(aspiration)으 로 인해 심한 불편감을 호소하며 적극적인 대안적 방법으로 서 수술적 치료를 희망하였다.

전신마취하 갑상피열근 절제술 및 선택적 반회후두신경절 제술 시행을 계획하였다. 전통적인 후두 미세 수술과 같은 방법으로 현수 후두경 하에 환자의 후두 부위를 확인하였고, $\mathrm{CO}_{2}$ 레이저를 이용하여 양측 후두실(ventricular fold) 일부
를 절제하여 양측 갑상 피열근을 노출시켰다. 성대 인대(vocal ligament)의 가장자리 및 갑상 연골의 연골막(perichondrium)을 각각 내측, 가측 경계로 하고, 후방으로는 성대돌 기(vocal process)를 경계로 하여 갑상 피열근의 중후방 부 위를 절제하였다. 이후 양측 성대 돌기 전방으로 비스듬하게 내측으로 주행하는 반회후두신경의 말단 분포를 확인한 뒤 이를 절제하였다(Fig. 1).

불규칙한 떨림 및 쥐어짜는 듯한 음성은 수술 직후부터 나 타나지 않았고, 출혈이나 흡인성 폐렴 등 합병증 없이 2일 간 의 입원 가료 이후 환자는 퇴원하였다. 술 후 약 2 주간 애성 및 사레들림을 호소하였으나, 수술 1개월 이후 외래 추적 관찰 상 후두 내시경 소견에서 발성 시의 불수의적인 과도한 경련 소견 및 성대 마비나 위축 등은 관찰되지 않았고, 주관적으로 애성 및 사레들림 증상 또한 호전되었다고 보고하였다. 수술 6 개월 이후 시행한 음성 분석 결과에서 주관적 음성평가 지표인 voice handicap index(VHI) 수치는 수술 전 35점에서 23점으 로 호전을 보였으며, 음성 검사상 악화 소견은 보이지 않았고 음성 단절 및 긴장성 노력음은 소실되었다(Table 1).

수술 후 5년간 정기적으로 외래에서 추적 관찰을 시행하 였고 후두 내시경 및 후두 스트로보스코피 검사상 성대의 움직임 및 점막의 파동은 정상이었다. 또한 발성 시의 불수 의적인 후두 경련은 보이지 않았으며 음성의 불규칙한 떨림, 단절, 쥐어짜는 듯한 목소리 등의 증상은 재발하지 않고 유 지되었다(Fig. 2). 수술 5년 후 시행한 VHI 수치는 15점으로 향상되었으며, voice visual analog scale(VAS) 및 aspiration 
VAS는 술 전 각각 6점, 4점에서 술 후 2점, 0점으로 호전되 었다고 보고하였다. 환자 수술에 대한 만족도(procedure satisfaction) VAS 또한 8점으로 높게 유지되는 상태로 외래 에서 추적 관찰 중에 있다(Table 1).

\section{고 찰}

연축성 발성장애의 원인이나 병태 생리는 정확하게 밝혀 져 있지 않으나 중추신경계의 운동 조절 장애에 기인한 국소 적인 근긴장 이상증의 한 형태로 추정되며, 증상 개선을 위 한 다양한 치료 방법이 시도되어 왔다. 갑상피열근 내 보툴리 눔 독소 주입술은 수 주일 내에 음성의 질 개선을 보이는 것 이 입증되어 현재 표준 치료로 자리 잡아 널리 사용되고 있 다.) 그러나 시술의 효과가 일시적이어서 음성의 변동성을 보 여(botox rollercoaster) 환자의 불편감을 초래하고, 수개월 간격으로 반복적인 시술을 요한다는 제한점이 있다. 또한 한 환자에서 반복적인 시술 시에 효과가 일정하지 않고, 환자 간
의 효과 차이가 크며, 개인적 특성에 따라 시술이 어려운 경 우가 존재하고, 시술자 간에 용량에 대한 정립된 기준이 부 족하다는 문제점을 가진다. ${ }^{3}$

따라서 보다 장기적이고 안정적인 치료 효과를 위해 수술 적 치료들이 고안되었는데, Berke 등는 선택적 후두 내전근 탈신경-재신경지배 수술(selective laryngeal adductor denervation-reinnervation surgery)을 시도하였다. 이는 전신 마취하 경부 절개 후 목신경고리(ansa cervicalis)를 박리한 뒤, 후두절개술(laryngotomy)을 통해 후두 내전근의 신경에 신경연결술을 시행하는 술식이다. 장기적으로 효과적이라고 보고되었으나, 광범위한 경부 절개를 통한 접근법으로서 미용 적으로 큰 단점이 있을 뿐만 아니라 수술 소요 시간이 길고 기술적으로도 어려워 보편적으로 시행하기에는 한계가 있다.

Issiki와 Tsuji5)가 시도한 2형 갑상성형술(type II thyroplasty)은 연축성 발성장애에서 발성 시에 과도한 성대의 접 촉으로 인해 증상이 발생한다는 점에 착안하여, 티타늄 금 속을 이용해 양측 성대 사이의 간격을 형성하여 증상을 호

Table 1. Preoperative and postoperative voice parameters

\begin{tabular}{|c|c|c|c|c|c|c|c|c|}
\hline & MPT (sec) & Jitter (\%) & Shimmer (\%) & NHR & $\begin{array}{l}\text { Voice } \\
\text { VAS }\end{array}$ & $\begin{array}{l}\text { Aspiration } \\
\text { VAS }\end{array}$ & VHI-10 & $\begin{array}{c}\text { Procedure satisfaction } \\
\text { VAS }\end{array}$ \\
\hline Pre & 6'80" & 0.29 & 2.61 & 20.69 & 6 & 4 & 35 & \\
\hline Post 6M & $10^{\prime} 08^{\prime \prime}$ & 0.14 & 0.89 & 31.96 & 4 & 2 & 23 & 3 \\
\hline Post 1Y & 8'49" & 0.17 & 1.03 & 31.05 & 6 & 6 & 24 & 5 \\
\hline Post 2Y & 7'69" & 0.21 & 1.32 & 25.47 & 4 & 4 & 7 & 8 \\
\hline Post 3Y & 6’85” & 0.13 & 0.92 & 30.63 & 6 & 4 & 24 & 5 \\
\hline Post 5Y & $12^{\prime} 13^{\prime \prime}$ & 0.16 & 1.77 & 28.03 & 2 & 0 & 15 & 8 \\
\hline
\end{tabular}

MPT: mean phonation time (s), NHR: noise to harmonics ratio, VAS: visual analogue scale, VHI: voice handicap index, M: month, Y: year
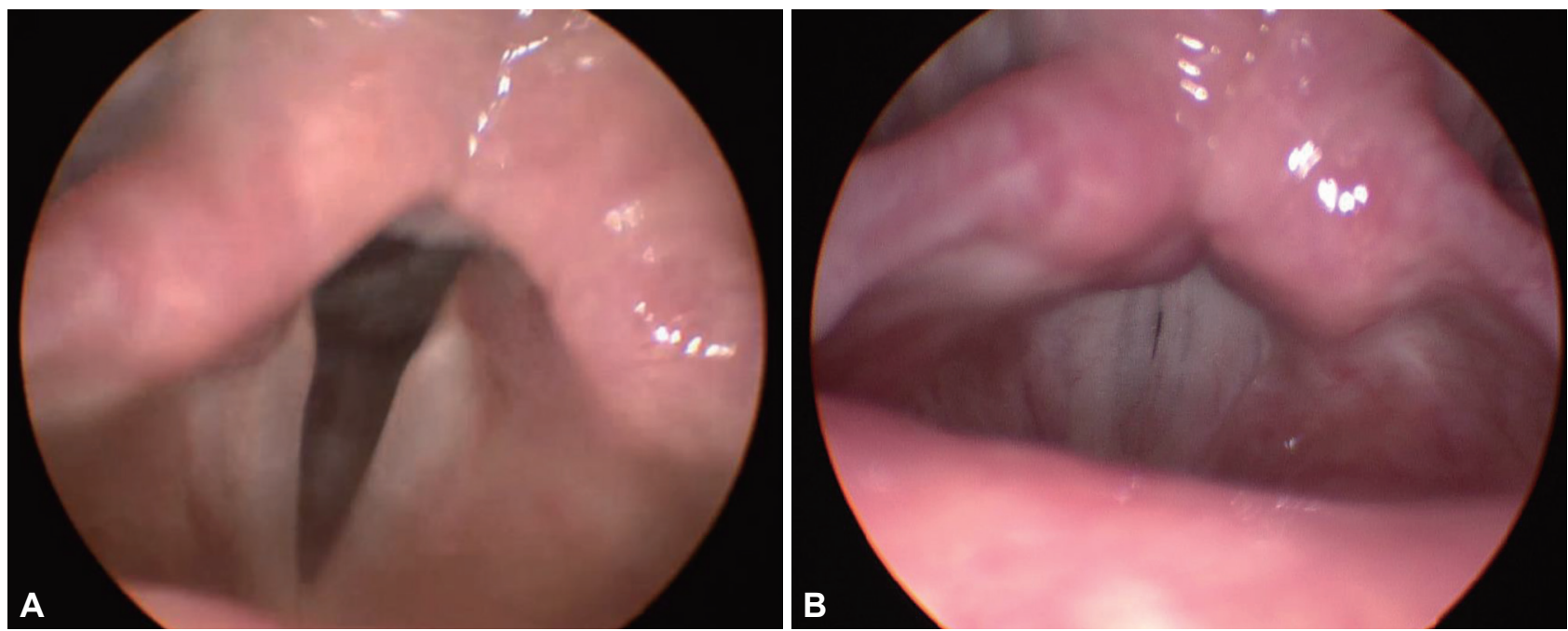

Fig. 2. Postoperative 5 years videostroboscopic exam. There is no evidence of recurrence or vocal fold atrophy, vocal cord paralysis. Both subjective and objective evaluation of voice quality is within the normal range without break or strain. Abduction (A). Adduction (B). 
전시키는 원리를 이용한 방법이다. 경부에 절개를 가하므로 미용적 측면의 문제가 있고, 티타늄 금속이 현재 국내에서는 사용 불가할 뿐만 아니라 효과가 지속적으로 유지되지 않는 제한점을 보였다.

갑상피열근 절제술 또는 반회후두신경 절제술을 단독으로 시행한 이전의 연구들은 효과적인 증상 호전을 보였으나 수 개월 이후 재발하는 한계를 보였다. ${ }^{6}$ 증상이 재발하는 기전 에 대해서는 정확히 알려지지 않았으나, 탈신경된 근섬유 (denervated muscle fibers)들이 신경재지배(reinnervation) 되기 때문일 것으로 추정된다.) 따라서, 이러한 재발을 방지 하기 위해 $\mathrm{Su}$ 등1,8)은 $\mathrm{CO}_{2}$ 레이저를 이용하여 후두실 일부와 갑상피열근 중 특히 운동 신경 종판(motor end plate)이 다 수 분포하는 것으로 알려진 후방부 3 분의 2 를 포함하여 절제 한 뒤, 갑상피열근에 분포하는 반회후두신경 말단부 절제술 을 함께 시행하는 술식을 제시하였고 실제로 치료 결과 음성 개선 효과가 우수하며 장기적으로 안정적으로 유지된다고 하였다. 또한 Tsuji 등)도 해당 술식에 대해 보고하였으며, 효 과적으로 반회후두신경 말단부 절제술을 시행하기 위해 특 수 고안된 전기소작기를 소개하였다. 최근 국내에서도 이 전 기소작기를 이용하여 본 술식을 통해 성공적인 치료 효과를 보고한 바 있다.9)

후두실을 포함하여 갑상피열근을 절제하는 원리는 연축 성 발성장애 환자에서 후두실의 과내전 및 과기능성이 자주 관찰되며, 실제로 일부 탄성 결합 조직(elastic connective tissue) 및 운동 신경 종판이 후두실에도 분포하고 있어 증상 유발에 기여할 것이라고 추정되기 때문이다. ${ }^{10)}$ 또한 장기적으 로 성대 인대 가측에 해당하는 근섬유 절제 부위에 섬유성 반흔(fibrotic scar)이 형성됨에 따라 양측 성대를 가측으로 당기는 힘이 발생하여 과도한 성대 내전을 예방하는 데 기여 할 것으로 생각된다.

약 1 4주 이후 술 후 발생하는 애성이나 흡인 등의 증상은 호전되고, 음성의 질이 빠르게 회복된다고 보고하였으며," 본 증례에서도 유사한 경과를 보였다. 5 년 간의 추적 관찰 기 간 동안 재발, 성대 마비, 성대 위축, 성대 휘어짐(bowing) 등 의 소견은 보이지 않았으며, 폐렴이나 삼킴 곤란 등의 합병증 은 동반되지 않았다. 이는 국내에서 보고된 본 술식에 대한 추적 관찰 중 가장 장기적인 것으로 의미를 가진다.

갑상피열근 절제술 및 선택적 반회후두신경 절제술은 기 존의 보툴리눔 독소 주입술에 치료 효과를 보이지 않거나, 반복적인 시술이 어려운 경우 또는 직업적으로 음성의 사용 이 필수적인 자 등 적절히 선별된 환자군을 대상으로 시도될 수 있는 효과적이고 안정적인 치료 대안으로 사료된다. 보다 많은 증례에 대한 지속적인 추적 관찰을 시행하여 본 술식의
안정성 및 장기적 효과를 파악할 수 있을 것으로 기대되는 바이다.

중심 단어: 연축성 발성장애, 갑상피열근 절제술, 보툴리눔 독소 주입술.

Acknowledgments

None.

Conflicts of Interest

The authors have no financial conflicts of interest.

\section{Authors' Contribution}

Conceptualization: Seung Won Lee. Data curation: Yun Ji Lee. Formal analysis: Yun Ji Lee, You Young An. Investigation: Yun Ji Lee, Seung Won Lee. Methodology: Yun Ji Lee, Seung Won Lee. Project administration: Yun Ji Lee, Seung Won Lee. Resources: Ki Nam Park, Seung Won Lee. Software: Yun Ji Lee, Seung Won Lee. Supervision: Ki Nam Park, Seung Won Lee. Validation: Yun Ji Lee, You Young An, Seung Won Lee. Visualization: Yun Ji Lee, You Young An, Ki Nam Park, Seung Won Lee. Writing—original draft: Yun Ji Lee. Writing—review \& editing: You Young An, Ki Nam Park, Seung Won Lee. Approval of final manuscript: all authors.

\section{REFERENCES}

1. Su CY, Chuang HC, Tsai SS, Chiu JF. Transoral approach to laser thyroarytenoid myoneurectomy for treatment of adductor spasmodic dysphonia: short-term results. Ann Otol Rhinol Laryngol 2007; 116(1):11-8.

2. Blitzer A, Brin MF, Stewart CF. Botulinum toxin management of spasmodic dysphonia (laryngeal dystonia): a 12-year experience in more than 900 patients. Laryngoscope 2015;125(8):1751-7.

3. Tsuji DH, Takahashi MT, Imamura R, Hachiya A, Sennes LU. Endoscopic laser thyroarytenoid myoneurectomy in patients with adductor spasmodic dysphonia: a pilot study on long-term outcome on voice quality. J Voice 2012;26(5):666.e7-12.

4. Berke GS, Blackwell KE, Gerratt BR, Verneil A, Jackson KS, Sercarz JA. Selective laryngeal adductor denervation-reinnervation: a new surgical treatment for adductor spasmodic dysphonia. Ann Otol Rhinol Laryngol 1999;108(3):227-31.

5. Isshiki N, Tsuji DH, Yamamoto Y, Iizuka Y. Midline lateralization thyroplasty for adductor spasmodic dysphonia. Ann Otol Rhinol Laryngol 2000;109(2):187-93.

6. Netterville JL, Stone RE, Rainey C, Zealear DL, Ossoff RH. Recurrent laryngeal nerve avulsion for treatment of spastic dysphonia. Ann Otol Rhinol Laryngol 1991;100(1):10-4.

7. Aronson AE, De Santo LW. Adductor spastic dysphonia: three years after recurrent laryngeal nerve resection. Laryngoscope 1983;93(1): $1-8$.

8. Su CY, Lai CC, Wu PY, Huang HH. Transoral laser ventricular fold resection and thyroarytenoid myoneurectomy for adductor spasmodic dysphonia: long-term outcome. Laryngoscope 2010;120(2): 313-8.

9. Lee SJ, Jung SY, Chung SM, Kim HS. A case of thyroarytenoid myoneurectomy using laser and monopolar electrical device in spasmodic dysphonia. J Korean Soc Laryngol Phoniatr Logoped 2019;30(2): 132-5.

10. Schönweiler R, Wohlfarth K, Dengler R, Ptok M. Supraglottal injection of botulinum toxin type A in adductor type spasmodic dysphonia with both intrinsic and extrinsic hyperfunction. Laryngoscope 1998;108(1 Pt 1):55-63. 